\title{
INVESTIGATION OF THERMO-PHYSICAL PROPERTIES OF DIATOMITE/WATER NANOFLUID
}

\author{
Sinan ÖZTAS \\ Gazi Üniversitesi, Mühendislik Fakültesi, Maltepe, Ankara \\ Uğur KARAKAYA \\ Gazi Üniversitesi, Kimya Mühendisliği, Maltepe, Ankara \\ Ümit ISKENDER \\ Turkish Airways, Yeşilköy, İstanbul, Turkey \\ e-mail: mehmetoz2011@gmail.com
}

\begin{abstract}
In this study, the thermo physical properties of the nanofluid obtained with prepared solution by adding as basic fluid $1.3 \%$ the diatomite nanoparticles into water were determined. Many researchers are working to improve the performance of heat transfer fluids. One of the methods used, if we want to increase the overall thermal conductivity of the fluid, the high thermal conductive materials such as metal oxides, metals and carbon should be added to heat transfer fluids as nano-sized particles. In this study, specific heat capacity, thermal conductivity and viscosity of nanofluid obtained with diatomite nanoparticles in order to increase the fluid's thermal performance and not found in the literature were investigated experimentally.
\end{abstract}

Keywords: nanofluids, diatomite, heat capacity, thermal conductivity. 


\section{INTRODUCTION}

Nanofluids, as a kind of new engineering material consisting of nanometer-sized additives and base fluids, have attracted great attention of investigators for its superior thermal properties and many potential applications. There are several methods to improve the heat transfer efficiency. These methods are increasing the surface area, improving the thermal conductivity and increasing the temperature between the two situations. However, increasing the surface area may not always be possible. Increasing the thermal conductivity is one of the most commonly applied method and different fluids are used for this. Nevertheless, the thermal conductivity of the fluids is very low, when compared to solid. The idea of putting high conductivity nano-sized solid particles into fluid for improving the thermal conductivity is one of the subjects studied for many years [1]. Thermal conductivity very good and the most widely used metallic solids particles; copper, aluminum, silver, gold and iron, nonmetallic solids solids particles; aluminum oxide $\left(\mathrm{Al}_{2} \mathrm{O}_{3}\right)$, cupric oxide $(\mathrm{CuO})$ Titanium dioxide $\left(\mathrm{TiO}_{2}\right)$, Zinc oxide $(\mathrm{ZnO})$, Silicon dioxide $\left(\mathrm{SiO}_{2}\right)$ have been defined[2]. Thermal conductivity enhancement of nanofluids depends on adding nanoparticles and the nanoparticle aspect ratio. Compared to conventional solid-liquid suspensions for heat transfer condensations, nanofluids dominates the following benefits. High specific surface area and therefore more heat transfer surface between particles and fluids. Increased thermal conductivity and exceptional theoretical predictions. Reduced pumping power as compared to pure liquid to achieve equivalent heat transfer intensification. Superior lubrication and decreased friction coefficient. Reduced particle clogging as compared to conventional slurries, thus promoting system miniaturization. Adjustable properties, including thermal conductivity and surface wettability, by varying particle concentrations to süit different applications [3]. However, adding nanoparticles increases viscosity of nanofluids which limits the thermal benefits of nanofluids. Maxwell was the first presenter of a theoretical basis to predict a suspensions effective conductivity about 143 years ago and his theory was applied from millimeter to micrometer sized particles suspensions, but Choi and Eastman have presented the novel concept of nanofluids by applying the unique properties of nanofluids at the annual Mechanical 
Engineering meeting of American Society at 1995 [4]. The works on this subject has been quite increased in recent years. Some of these studies are summarized below.

Xuan and Li experimentally determined the degree of enhancement in convective heat transfer coefficient and friction factor in a compact heat exchanger using copper-water nanofluids. The experimental studies concluded that an enhancement in heat transfer can be achieved using nanofluids with negligible increase in pumping power [5]. Zhen-Hua Liu et al. have reviewed and summarized the research done on heat pipes using nanofluids as working fluids in recent years. In other words, the effect of characteristics and mass concentrations of nanoparticles on the thermal performance in various kinds of heat pipes with different base fluids under various operating conditions have been explored by they. As a result, they have shown that nanofluids have great application prospects in various heat pipes [6]. Akbarinia et al. have investigated to study heat forced convection $\mathrm{Al}_{2} \mathrm{O}_{3}$ - water nanofluid flows in two-dimensional rectangular microchannels transfer enhancement due to addition of the nanoparticles to the base fluid especially in microchannels at low Reynolds number in this study. it is found that constant Reynolds number studies of nanofluids are not sufficient approach to evaluate the heat transfer and the skin friction factor due to the nanofluids usage by they [7]. Ravikumar et al. have studied enhancement of cooling rate of an AISI 304 steel plate by air atomized spray cooling with different types of surfactant additives. As a results, it was found that enhanced ultrafast cooling rates can be useful to produce advanced high strength steels in the steel industries [8]. Mahian et al. have investigated the nanofluids' applications in solar thermal engineering systems. It was found that the effects of nanofluids on the performance of solar collectors and solar water heaters from the efficiency, economic and environmental considerations viewpoints by they [9]. Gunnasegaran et al. investigated the LHP performance using silica (SiOH) nanofluid and FEM simulation investigations with particle volume fraction of $3 \%$ and which was used as a coolant in this study. It was found that the presence of nanoparticles greatly enhance the cooling of LHP, and the experimental and simulation results were found in good agreement [10]. Fang et al. investigated on the flow boiling heat transfer of nanofluids, with an emphasis on the heat transfer coefficient (HTC), critical heat flux (CHF), pressure drop, nanofluid stability, 
flow and heat transfer mechanism, and flow pattern and bubble dynamics. The important achievements, inconsistence, and contradictions of the existing research results are identified, and several topics worthy of attention for future investigations are identified [11]. Hemmat Esfe et al. researched an experimental study of Fe-water nanofluids to investigate the effective thermal conductivities and dynamic viscosity of water-based nanofluids containing Fe nanoparticles [12]. Duangthongsuk et al. have experimentally investigated the thermal and hydraulic performances of $\mathrm{SiO}_{2}$-water and $\mathrm{ZnO}$-water nanofluids with particle volume fraction of $0.2,0.4$ and 0.6 vol.\% flowing through miniature circular pin fin heat sink [13]. Mehrali et al. investigated the impact of the dispersed nanoparticles concentration on thermal properties, convective heat transfer coefficient, thermal performance factor and entropy generation. They observed an enhancement in thermal conductivity for GNP of between $12 \%$ and $28 \%$ relative to the case without nanoparticles. It was found that the convective heat transfer coefficient for the GNP nanofluid is up to $15 \%$ higher than for the base fluid. However, they observed that the total entropy generation tends to decrease when nanoparticles are added at constant velocity and to decrease when velocity rises. Finally, it was demonstrated that a GNP nanofluid with a concentration between $0.075 \mathrm{wt} . \%$ and $0.1 \mathrm{wt} . \%$ is more energy efficient than for other concentrations [14].

Akhavan-Behabadi et al. made an investigation on thermal-rheological properties and heat transfer behavior of the heat transfer oil-copper oxide (HTO-CUO) nanofluid in smooth tubes. In addition, the heat transfer coefficient and the performance index of the HTO-CuO nanofluid flow in smooth tubes were also studied. As a result, they found that the nanoparticle enhances the volumetric thermal expansion, viscosity, and thermal conductivity of the base fluid while decreases its specific heat [15]. Li et al. researched the thermal conductivity and viscosity of ethylene glycol based ZnO nanofluids. They carried out that thermal conductivity increased slightly with increasing the temperature from 15 to $55^{\circ} \mathrm{C}$ and it was dependent strongly on particle concentration and increased nonlinearly with the concentration within the range studied. Moreover, they found that viscosity increased with concentration as usual for $\mathrm{ZnO}$ nanoparticles and decreased with temperature [16]. Shafahi et al. investigated the thermal performance of a cylindrical heat pipe utilizing nanofluids with using the most common nanoparticles $\left(\mathrm{Al}_{2} \mathrm{O}_{3}\right.$, 
$\mathrm{CuO}$, and $\mathrm{TiO}_{2}$ ). When using a nanofluid, they found a substantial change in the heat pipe thermal resistance, temperature distribution, and maximum capillary heat transfer of the heat pipe [17]. Yousefi et al. investigated the effect of MWCNT nanofluid, as absorbing medium, on the efficiency of a flat-plate solar collector as experimentally. As a results, they observed that using the $0.2 \mathrm{wt} \%$ MWCNT nanofluid without surfactant decrease the efficiency and with surfactant increase it. In addition, for 0.4 wt\% MWCNT nanofluid without surfactant an increase for the efficiency was observed [18].

Moraveji et al. investigated the effect of using aluminum oxide nanofluid (pure water mixed with $\mathrm{Al}_{2} \mathrm{O}_{3}$ nanoparticle with $35 \mathrm{~nm}$ diameter) on the thermal efficiency enhancement of a heat pipe on the different operating state in this research. In other words, the thermal enhancement of the grooved heat pipe performance by charging $\mathrm{Al}_{2} \mathrm{O}_{3}$ nanofluid as the working fluid inside a 1 $\mathrm{mm}$ wick-thickness sintered circular heat pipe which is experimentally was tested. Results show that by charging the nanofluid to the heat pipe, thermal performance is enhanced by reducing the thermal resistance and wall temperature difference [19]. Khedkar et al. studied on an experimental study on concentric tube heat exchanger for water to nanofluids heat transfer with various concentrations of nanoparticles in to base fluids and application of nanofluids as working fluid. It observed that, $3 \%$ nanofluids shown optimum performance with overall heat transfer coefficient $16 \%$ higher than water [20]. Fontes et al. investigated that experimental results of the thermal conductivity, viscosity and breakdown voltage of solutions of diamond nanoparticles and multiwalled carbon nanotubes dispersed in mineral insulating oil for electrical transformers. From the experimental results, it was found that thermal conductivity and dynamic viscosity increase with increasing the particle concentration. On the other hand, and similarly to what is observed in the literature, the addition of these nanoparticles to the oil decreases its breakdown voltage [21]. Hemmat Esfe et al. investigated the effect of nanoparticle volume fraction on thermal conductivity and dynamic viscosity of $\mathrm{Ag}-\mathrm{MgO} /$ water hybrid nanofluid with the particle diameter of $40(\mathrm{MgO})$ and $25(\mathrm{Ag}) \mathrm{nm}$ and nanoparticle volume fraction ( $50 \% \mathrm{Ag}$ and $50 \% \mathrm{MgO}$ by volume) range between $0 \%$ and $2 \%$ and presenting new correlations. According to results with increasing the nanoparticle volume fraction, thermal conductivity and dynamic viscosity of nanofluid increase an presented correlations show 
higher values in comparison to other existing correlations in literature [22]. Abdellahoum et al. researched the several models of the viscosity of turbulent forced convection of $\mathrm{Al}_{2} \mathrm{O}_{3}$ nanofluid over a heated cavity in a horizontal duct in this study. They found that this work leads to further investigations for viscosity of nanofluids in forced convection in separated flow, experimentally and numerically [23].

Solangi et al. have presented an inclusive overview of recent investigations on the thermophysical properties of nanofluids and their role in heat transfer enhancement from different applications. In other words, they have presented that an updated review of properties of nanofluids, such as physical (thermal conductivity) and rheological properties, with emphasis on their heat transfer enhancement characteristics in this study [24]. Haddad et al. have observed the nanofluid preparation methods reported by different investigators in an attempt to find a suitable method for preparing stable nanofluids. They have used three methods for prepare nanofluids. These methods are sonication, $\mathrm{pH}$ control and Surfactants [25]. John Philip et al. investigated thermal properties of nanofluids. In other words, in this study provides an overview of recent advances in the field of nanofluids, especially the important material properties that affect the thermal properties of nanofluids and novel approaches to achieve extremely high thermal conductivities. Though the modest thermal conductivity enhancement in stable nanofluids is a cause of concern for practical applications, it is found that novel approaches to achieve thermal conductivity enhancement close to parallel modes of conduction is very promising for innovative cooling applications [26]. Utomo et al. have investigated thermal conductivity, viscosity and heat transfer coefficient of water-based alumina and titania nanofluids. Results showed that titania and alumina nanofluids do not show unusual enhancement of thermal conductivity heat transfer coefficients in pipe flow frequently reported in literature [27]. Mukesh Kumar et al. investigated the heat transfer coefficient and pressure drop of a helically coiled tube heat exchanger handling $\mathrm{Al}_{2} \mathrm{O}_{3}$ /water nanofluids is made by using computational fluid dynamics fluent (CFD) software package. They observed that the developed CFD model gives good prediction for heat transfer coefficient and pressure drop in a helically coiled tube heat exchanger. Moreover, they observed that CFD work is needed by considering two phase flow model, higher nanoparticles concentration and at higher De values for 
prediction of heat transfer coefficient and pressure drop [28]. Hajian et al. researched the response time based on the variation of the heat pipe surface temperature. The experiments in this study were performed as using suspensions of silver nanoparticles in DI-water in various concentrations of 50, 200 and $600 \mathrm{ppm}$. As a result, it is found that whereas the heat pipe operation with DI-water was more stable, by using nanofluids, the thermal resistance and response time of the heat pipe decreased up to $30 \%$ and $20 \%$, respectively, compared to DI-water [29]. Yanjun Li et al. have investigated experimentally that transition regime convection heat transfer coefficients of Zinc Oxide/Ethylene Glycol-Water (ZnO/EG-W) nanofluid in a circular pipe where the mass fraction of nanoparticles in the base fluid is from 0 to $5 \mathrm{wt} . \%$, and operating temperatures. As a result, it was found that the nanofluid has maximum of $30 \%$ higher heat transfer coefficient compared to base fluid at mass fraction of $2.5 \mathrm{wt} . \%$. Whereas, at higher values of the nanoparticles mass concentrations $5 \mathrm{wt} . \%$, the heat transfer coefficient decreases. Furthermore, results demonstrated that the $\mathrm{ZnO} / \mathrm{EG}-\mathrm{W}$ nanofluid might be promising alternatives for conventional coolants [30]. Chung et al. researched the effectiveness of ultrasonic dispersion. They found that processing volumes should be kept small, or mixed well by mechanical stirring during the process so as to circulate all material through the cavitation field [31].

So far in the studies, it was usually worked on nanofluids containing metal oxide. The availability in thermal systems of the obtained nanofluids has been investigated. Thermo-physical properties of the fluid must be determined to be used in simulations and theoretical calculations of thermal systems. Thermodynamic properties of the obtained nanofluid from diatomite with this study were determined. In additions to, it has been presented advices for the disadvantage elimination of the precipitation and grounding very common in the literature.

\section{DIATOMITE}

Diatomite is a powdery, non-metallic mineral composed of the fossilized skeletal remains of microscopic single-celled aquatic plants called diatoms. The unique properties of diatomite including: 
- Light weight

- High porosity

- High absorptivity

- High purity

- Multi-shaped

- Rigidity

- Inertness

make it industrially useful in a variety of ways such as in liquid filtration; as a multi-functional mineral additive; as a carrier for active ingredients and diluents; as an aggregate; and, as a source of silica to name just a few.

Each deposit of diatomaceous earth is different, with varying blends of pure diatomaceous earth combined with other natural clays and minerals. The diatoms in each deposit contain different amounts of silica, depending on the age of the deposit. As well, the species of diatom may also differ among deposits. The species of diatom is dependent upon the age and paleoenvironment of the deposit. In turn, the shape of a diatom is determined by its species.

The typical chemical composition of oven-dried diatomaceous earth is 80 to $90 \%$ silica, with 2 to $4 \%$ alumina (attributed mostly to clay minerals) and 0.5 to $2 \%$ iron oxide. This study is being removed from the used diatomite Ankara's Ayaş district in content are given in Table 1.

Table 1. Chemical Composition of Diatomite

\begin{tabular}{|c|c|c|c|c|c|c|c|}
\hline $\begin{array}{c}\text { Chemical } \\
\text { structure }\end{array}$ & $\mathrm{SiO}_{2}$ & $\mathrm{Al}_{2} \mathrm{O}_{3}$ & $\mathrm{Fe2O3}$ & $\mathrm{CaO}$ & $\mathrm{MgO}$ & $\begin{array}{l}\text { Other } \\
\text { oxide }\end{array}$ & $\mathrm{S}$ \\
\hline$\%$ & 92.80 & 4.2 & 1.5 & 0.6 & 0.3 & 0.50 & 0.01 \\
\hline
\end{tabular}




\section{EXPERIMENTAL PROCEDURE}

\subsection{Nanofluid preparation}

The size of the diatomite particles was reduced $(\sim 50 \mathrm{~nm})$ and refined to a uniform particle size prior to any further processing via Spex-8000 ball milling (Spex Industries, Inc., Edison, NJ). The size has a normal distribution in a range from $40-100 \mathrm{~nm}$ (50 nm average diameter) as shown in Fig.1. The nanofluid had 1,3\% (wt/wt) nano-particle content. Nano-particles of diatomite was suspended in the base fluid (water) and the mixture was enhanced by the addition of Triton X-100 (surfactant) to a final concentration of $0.5 \%$ with the aim of increasing solubility of the diatomite. The diatomite nano-particles were dispersed in deionized water through continuous pulsing for 8 hours using an ultrasonic processor (Bandelin Sonorex Super RK514H). The container was regularly cooled to prevent the evaporation of the surface active agent during the preparation of the nanofluid. It is important to prevent of the sedimentation of nano fluid in the experiment. Firstly, the size of diatomite was decreased to the nanoform by means of high energy impacted ball milling (Spex-8000). Secondly, surface agent called Triton X 100 was added to the diatomite solution. Finally, nano diatomite was solved in the water by ultrasonic bath. Since the density difference between metallic oxide nanoparticles and deionized water is large, two kinds of techniques have been suggested to disperse well and prevent the sedimentation of nanoparticles in the nanofluids. One is to change $\mathrm{pH}$ of the nanofluid and the other is using of surfactants. Due to the amorphous structure of the different metal oxides present in the diatomite nanoparticles that are used in the study, the use of Triton X 100 as the surfactant allowed the particles to disperse in deionized water. The nanofluid was obtained using varying ratios of surfactant and the optimal nanofluid with minimal agglomeration was achieved at a surfactant ratio of $0.2 \%$. The suspension of the nanofluid prior to and following the experiment were displayed in Fig. 2. 


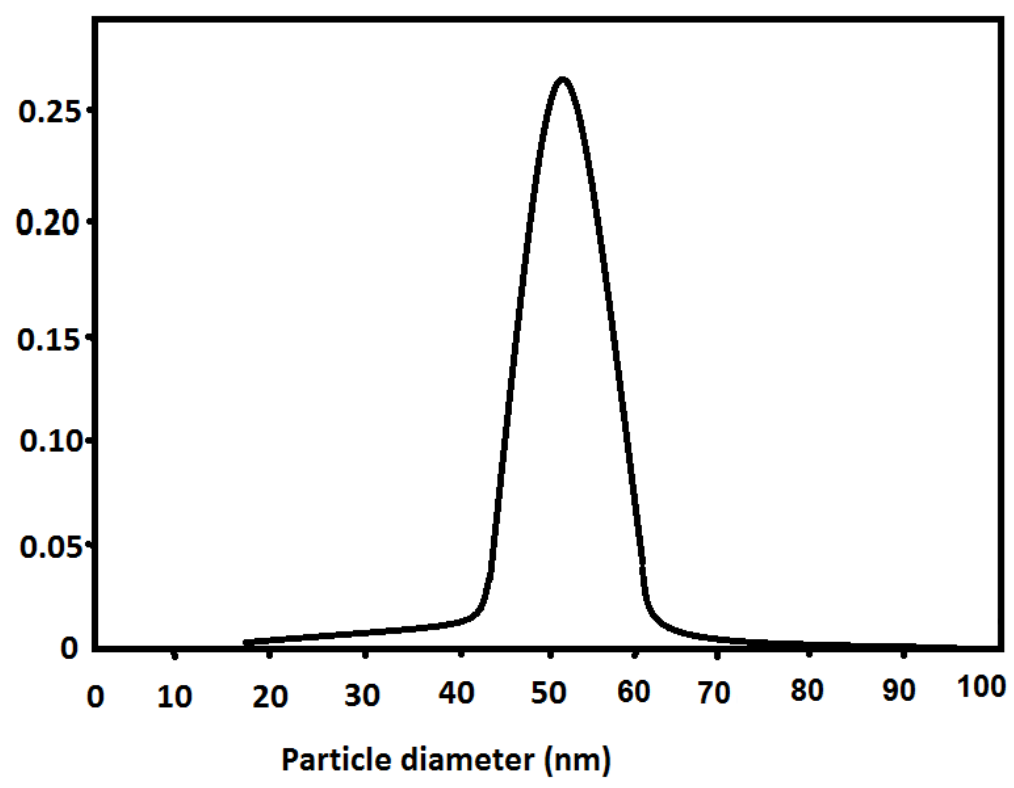

Fig. 1. Size distribution of the nano-particles.

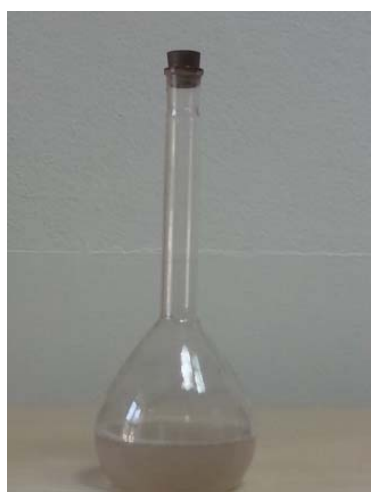

(a)

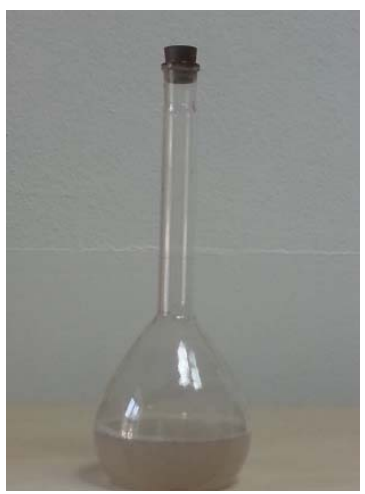

(b)

Fig. 2.Stability photograph of diatomite nanofluid (a): before experiment (b) after experiment 


\subsection{Thermo-physical Properties}

\subsubsection{Density}

Density, viscosity, specific heat capacity and thermal conductivity thermo physical properties of the nanofluid were measured by the following methods. The measurement of density, the determined volume of nanofluid by weighing with precision scales is calculated with the following formula.

$$
\rho=\frac{m}{V}
$$

\subsubsection{Viscosity}

The measurement of viscosity, viscosity is known as the resistance to flow of the fluid. In measuring the viscosity is used rotational method, the most commonly used method in scientific studies. The measurement of rotational viscosity is based on measurement of the rotational speed of the shaft and torque required to rotate the shaft. Rotational viscometer, belong to the 'Brookfield' brand, has been used in the experiments conducted and the measurement data is calculated with Rheocale V2.7 software. The experimental setup for viscosity measurement is seen in Fig. 3.

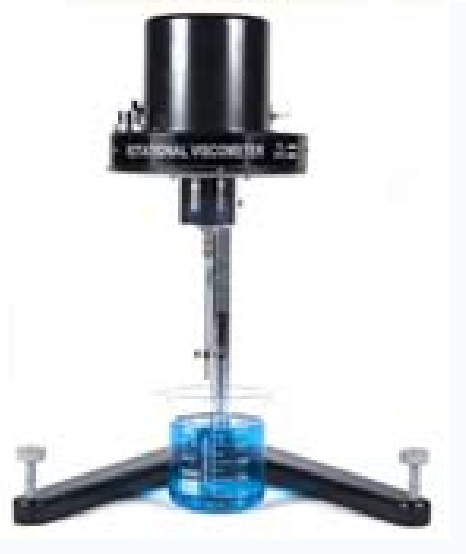

Fig. 3. Rotational viscometer

\subsubsection{Specific heat capacity}

Specific heat capacity (c) is the measure of the heat energy required to increase the temperature of $a$ unit quantity of a substance by a 
certain temperature interval. If the mass $(\mathrm{m})$ which is a substance is transferred $(Q)$ much energy with heat path, temperature of the object varies up to $(\Delta T)$ and specific heat is calculated by the following formula.

$$
c=\frac{Q}{m \Delta T}
$$

It should be given energy as specific heat for ensure a specific temperature change. Specific heat is also an indication of the energy stored in the materials. It is desired that high specific heat in the nanofluid. Specific heat capacity in our experiment has been measured by using differential calorimeter.

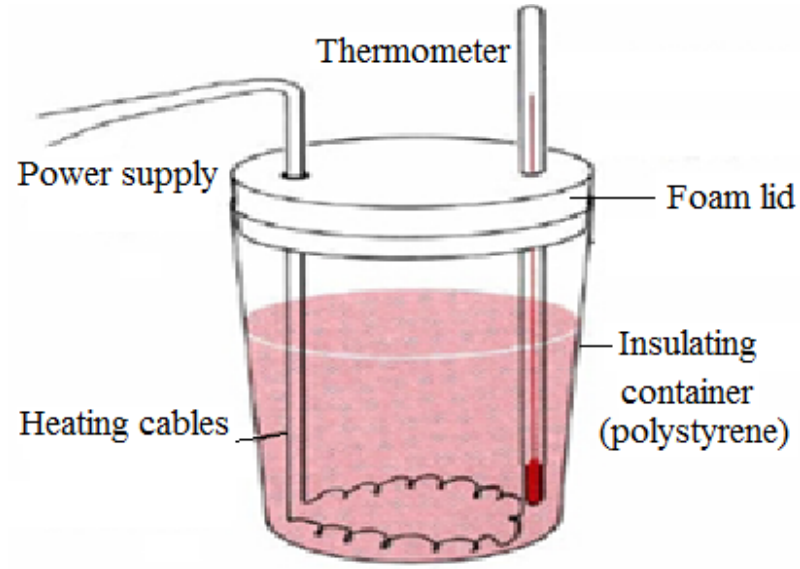

Fig. 4. Specific heat capacity measuring device

A calorimeter is a device used to measure the quantity of heat transferred to or from an object (Fig. 4). Cover and outer surfaces coated with a dielectric material, so that put into the cup one cold and the other hot heat transfer between two substances is realized independent from the external environment. Temperature change in the cup and equilibrium temperature are measured with thermocouples every 5 seconds and are transferred to the computer with the help of a data logger.

Putting together in an isolated mechanism against external environment and different temperatures between liquids are heat exchange. This heat exchange is expressed by the following equation; 


$$
\begin{aligned}
& Q_{\text {in }}=Q_{\text {out }} \\
& Q_{\mathrm{h}, \mathrm{w}}=Q_{\mathrm{c}, \mathrm{w}}+Q_{\text {container }} \\
& m_{h} c \Delta T_{h}=m_{c} c \Delta T_{c}+C_{\text {container }} \Delta T_{h} \\
& C_{\text {container }}=\left(Q_{h-} Q_{c}\right) / \Delta T_{h}
\end{aligned}
$$

is calculated as in equation.

\subsubsection{Thermal Conductivity}

The experimental setup for measuring the thermal conductivity of nanofluid; it consists of two parts, cylindrical measuring unit and including the main console. Schematic picture of cylindrical measuring unit and the main console is shown in Fig. 5. The space which between water-cooled jacket with heated piston filled up with fluid that will be detected thermal conductivity. The gap interval is not thin enough to allow the natural convection of fluids and the fluid surface area $\left(\pi d_{m} l\right)$ and the thickness $(\Delta r)$ which is a plate the heat transfer from piston side to jacket side.

At the outermost portion of the cylindrical measuring unit has cooling water jacket being provided with sealing gaskets. The heater in the cylindrical measuring unit is controlled via the main console. Aluminum plug and cooling water temperature are read from a digital temperature display on the main console with the help of thermocouples. Measurement data is transferred to the computer with the help of a data logger. 


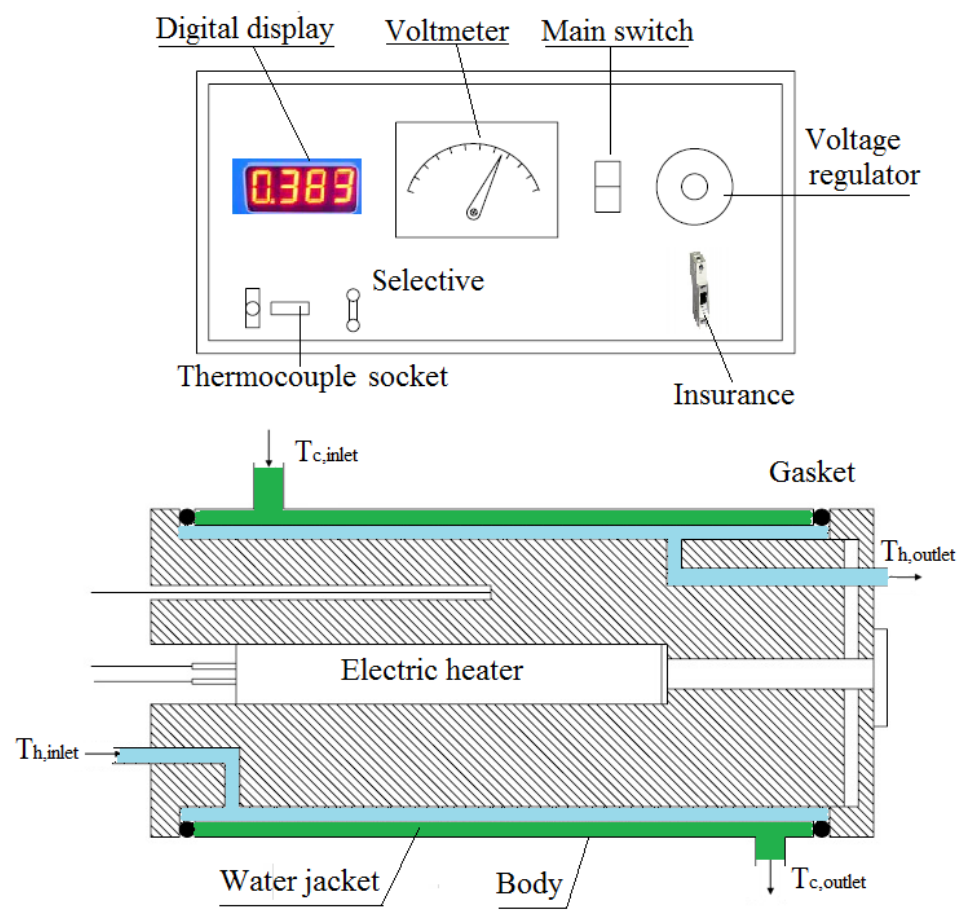

Fig. 5. Measuring the thermal conductivity of the fluid and cylindrical measuring unit

\subsubsection{Theoretical analysis}

Heat transfer coefficient is calculated with designed experimental setup as follows.

Heat load of hot fluid $\left(\dot{\mathrm{Q}}_{h}\right)$ is calculated by the following formula.

$\dot{\mathrm{Q}}_{h}=\dot{m}_{h} \cdot c_{p, h} \cdot\left(T_{h, \text { inlet }}-T_{h, \text { outlet }}\right)$

Transfering heat from the hot fluid to cold fluid in the heat exchanger;

$\dot{\mathrm{Q}}_{c}=\dot{m}_{c} \cdot c_{p, c} \cdot\left(T_{c, \text { outlet }}-T_{c, \text { inlet }}\right)$

has been calculated with the formula.

Taken heat from hot fluid is equal to given heat from the cold fluid. 


$$
\dot{\mathrm{Q}}_{h}=\dot{\mathrm{Q}}_{c}
$$

The heat transfer between the fluid with the pipe surface in transition temperature of the pipe is determined in Eq.4.

$$
\left.\dot{\mathrm{Q}}=h \cdot A \cdot \Delta T_{l n}\right)
$$

Where $\mathrm{h}$ is the convective heat transfer coefficient between the fluid and the inner surface of the pipe, A is the area of the heat transfer of inner surface of the pipe.

As seen in Eq.10, $\Delta T_{l n}$ is the logarithmic mean temperature difference between the fluid and inner surface of the tube.

$$
\Delta T_{\text {In }}=\frac{\Delta T_{\text {inlet }}-\Delta T_{\text {outlet }}}{\operatorname{In}\left(\frac{\Delta T_{\text {inlet }}}{\Delta T_{\text {outlet }}}\right)}
$$

\section{RESULTS}

The viscosity values depending on the temperature of diatomite is shown in Fig.6.

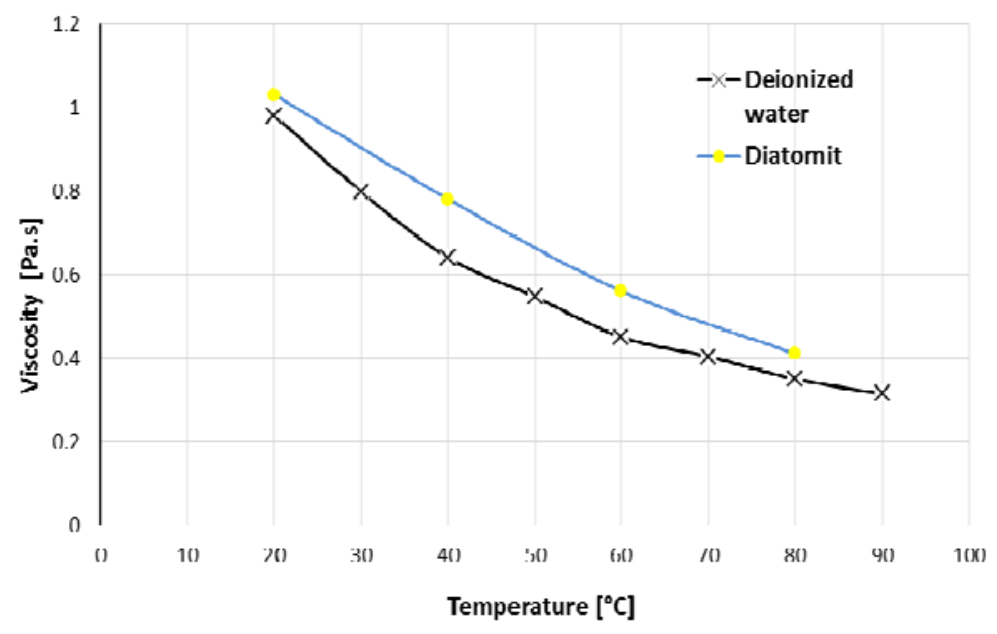

Fig. 6. Diatomite and water viscosity comparisons 
The viscosity of nanofluids containing diatomite decreases with temperature. Considering the availability of thermal systems can be said to be a suitable solution for high temperature applications $\left(80{ }^{\circ} \mathrm{C}\right)$. As a result of conducted experiments with the calorimeter, the nanofluid specific heat capacity of $4.27 \mathrm{~kJ} / \mathrm{kgK}$ have been identified. Compared with the other water is understood that a higher heat capacity ratio of $2.15 \%$.

In order to make comparison with experimental results reported in the literature for testing the accuracy of thermal conductivity experiments were performed for pure water. After the accuracy of the results obtained was proved, the nanofluids experiments containing diatomite were performed. The results are given in Fig.7.

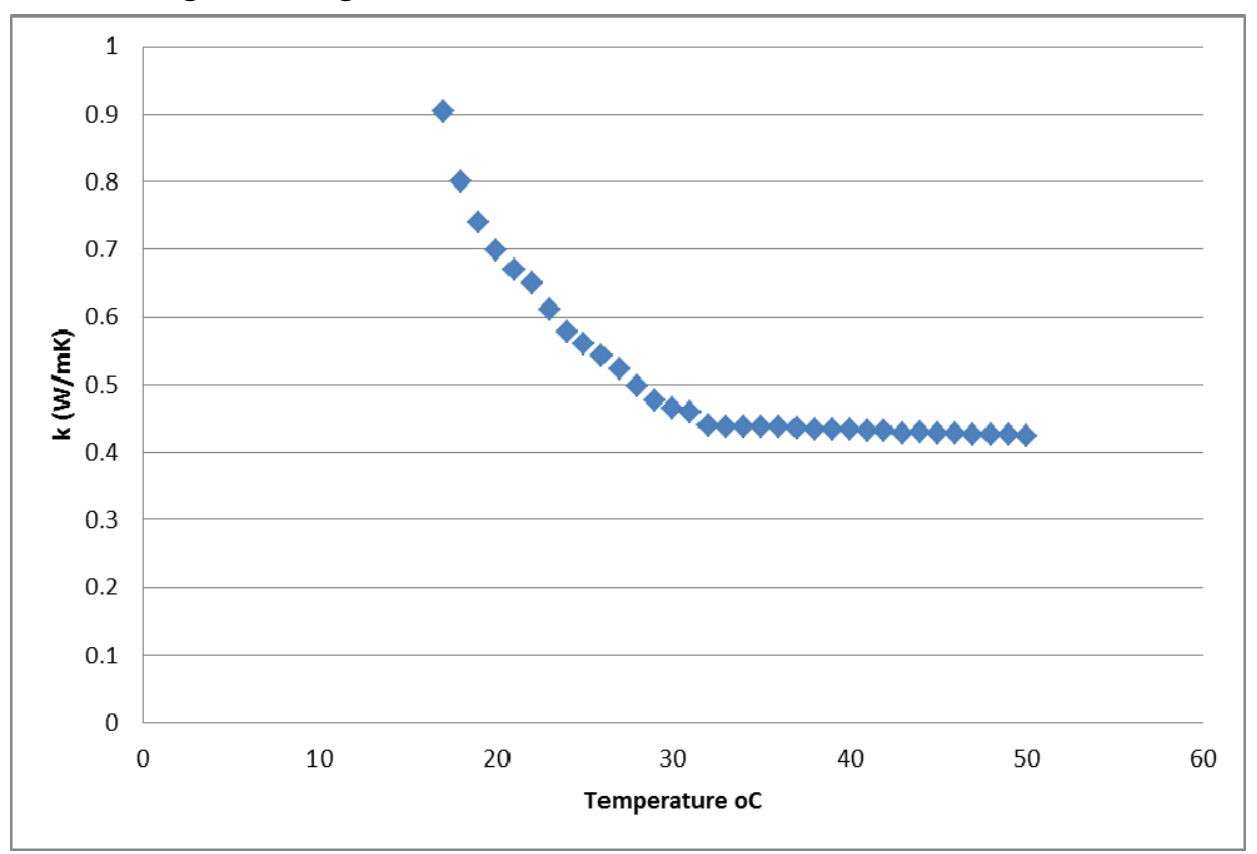

Fig.7. Experimental heat transfer coefficient for diatomite nanofluid 


\section{CONCLUSION}

The nanofluids containing nano-sized metal and metal oxide particles have been shown higher performance in terms of thermal conductivity. As a result of the conducted experiments, the diatomite nanofluid in terms of thermal conductivity compared to pure water has been found to perform better. It was observed that the thermal conductivity increases as the temperature increases.

The specific heat capacity is the amount of heat per unit mass required to raise the temperature by one degree Celsius. As a result of the conducted experiments, the specific heat value of diatomite nanofluids were found to be greater than pure water.

Finally, the viscosity value of diatomite nanofluid was found to be larger than pure water. Moreover, it was observed that the viscosity value of nanofluid decreases as temperature increases.

\section{REFERENCES}

[1] A. Ghadimi, R. Saidur, H.S.C. Metselaar, A review of nanofluid stability properties and characterization in stationary conditions, International Journal of Heat and Mass Transfer 54 (2011) 4051-4068.

[2] K.H. Solangi, S.N. Kazi , M.R. Luhur , A. Badarudin , A. Amiri, Rad Sadri, M.N.M. Zubir, Samira Gharehkhani, K.H. Teng, A comprehensive review of thermo-physical properties and convective heat transfer to nanofluids, Energy 89 (2015) 1065-1086.

[3] R. Saidura, K.Y. Leong, H.A. Mohammad, A review on applications and challenges of nanofluids, Renewable and Sustainable Energy Reviews 15 (2011) 1646-1668.

[4] Yanjiao Li, Jing'en Zhou, Simon Tung, Eric Schneider, Shengqi Xi, A review on development of nanofluid preparation and characterization, Powder Technology 196 (2009) 89-101.

[5] Y. Xuan, Q. Li, Investigation on convective heat transfer and flow features of nanofluids, J. Heat Transfer 125 (2003) 151-155.

[6] Zhen-Hua Liu, Yuan-Yang Li, A new frontier of nanofluid research-Application of nanofluids in heat pipes, International Journal of Heat and Mass Transfer 55 (2012) 6786-97.

[7] A. Akbarinia, M. Abdolzadeh , R. Laur, Critical investigation of heat transfer enhancement using nanofluids in microchannels with slip and non-slip flow regimes, Applied Thermal Engineering 31 (2011) 556-565.

[8] Satya V. Ravikumar, Jay M. Jha, Ishita Sarkar, Soumya S. Mohapatra, Surjya K. Pal, Sudipto Chakraborty, Achievement of ultrafast cooling rate in a hot steel plate by air-atomized spray with different surfactant additives, Experimental Thermal and Fluid Science 50 (2013) 79-89. 
[9] Omid Mahian, Ali Kianifar, Soteris A. Kalogirou, loan Pop, Somchai Wongwises, A review of the applications of nanofluids in solar energy, International Journal of Heat and Mass Transfer 57 (2013) 582-594.

[10] P. Gunnasegaran, M.Z. Abdullah , N.H. Shuaib, Influence of nanofluid on heat transfer in a loop heat pipe, International Communications in Heat and Mass Transfer 47 (2013) 82-91.

[11] Xiande Fang, Run Wang, Weiwei Chen, Helei Zhang, Chunxiang Ma, A review of flow boiling heat transfer of nanofluids, Applied Thermal Engineering 91 (2015) 1003-1017.

[12] Mohammad Hemmat Esfe, Seyfolah Saedodin, Somchai Wongwises, Davood Toghraie, An experimental study on the effect of diameter on thermal conductivity and dynamic viscosity of Fe/water nanofluids, J Therm Anal Calorim (2015) 119:1817-1824.

[13] Weerapun Duangthongsuk, Somchai Wongwises, An experimental study on the thermal and hydraulic performances of nanofluids flow in a miniature circular pin fin heat sink, Experimental Thermal and Fluid Science 66 (2015) 28-35.

[14] Mohammad Mehrali, Emad Sadeghinezhad, Marc A. Rosen, Amir Reza Akhiani , Sara Tahan Latibari, Mehdi Mehrali , Hendrik Simon Cornelis Metselaar, Heat transfer and entropy generation for laminar forced convection flow of graphene nanoplatelets nanofluids in a horizontal tube, International Communications in Heat and Mass Transfer 66 (2015) 23-31.

[15] M.A. Akhavan-Behabadi, F. Hekmatipour, S.M. Mirhabibi , B. Sajadi, Experimental investigation of thermal-rheological properties and heat transfer behavior of the heat transfer oil-copper oxide (HTO-CuO) nanofluid in smooth tubes, Experimental Thermal and Fluid Science 68 (2015) 681-688.

[16] Haoran Li, Li Wang, Yurong He*, Yanwei Hu, Jiaqi Zhu, Baocheng Jiang, Experimental investigation of thermal conductivity and viscosity of ethylene glycol based $\mathrm{ZnO}$ nanofluids, Applied Thermal Engineering 88 (2015) 363-368.

[17] Maryam Shafahi, Vincenzo Bianco, Kambiz Vafai, Oronzio Manca, An investigation of the thermal performance of cylindrical heat pipes using nanofluids, International Journal of Heat and Mass Transfer 53 (2010) 376-383.

[18] Tooraj Yousefi, Farzad Veisy, Ehsan Shojaeizadeh, Sirus Zinadini, An experimental investigation on the effect of MWCNT-H 20 nanofluid on the efficiency of flat-plate solar collectors, Experimental Thermal and Fluid Science 39 (2012) 207-212.

[19] Mostafa Keshavarz Moraveji, Sina Razvarz, Experimental investigation of aluminum oxide nanofluid on heat pipe thermal performance, International Communications in Heat and Mass Transfer 39 (2012) 1444-1448.

[20] Rohit S. Khedkar, Shriram S. Sonawane*,Kailas L Wasewar, Water to Nanofluids heat transfer in concentric tube heat exchanger:Experimental study, Procedia Engineering 51 (2013) $318-323$.

[21] Douglas Hector Fontes, Gherhardt Ribatski , Enio Pedone Bandarra Filho, Experimental evaluation of thermal conductivity, viscosity and breakdown voltage AC of nanofluids of carbon nanotubes and diamond in transformer oil, Diamond \& Related Materials 58 (2015) 115-121.

[22] Mohammad Hemmat Esfe, Ali Akbar Abbasian Arani, Mohammad Rezaie, Wei-Mon Yan, Arash Karimipour, Experimental determination of thermal conductivity and dynamic 
viscosity of $\mathrm{Ag}-\mathrm{MgO} /$ water hybrid nanofluid, International Communications in Heat and Mass Transfer 66 (2015) 189-195.

[23] Chahrazed Abdellahoum , Amina Mataoui, Hakan F. Oztop, Comparison of viscosity variation formulations for turbulent flow of $\mathrm{Al}^{2} \mathrm{O}^{3}$-water nanofluid over a heated cavity in a duct, Advanced Powder Technology 26 (2015) 1210-1218.

[24] K.H. Solangi, S.N. Kazi, M.R. Luhur, A. Badarudin, A. Amiri, Rad Sadri, M.N.M. Zubir, Samira Gharehkhani, K.H. Teng, A comprehensive review of thermo-physical properties and convective heat transfer to nanofluids, Energy 89 (2015) 1065-1086.

[25] Zoubida Haddad, Chérifa Abid, Hakan F. Oztop, Amina Mataoui, A review on how the researchers prepare their nanofluids, International Journal of Thermal Sciences 76 (2014) 168-189.

[26] John Philip, P.D. Shima, Thermal properties of nanofluids, Advances in Colloid and Interface Science 183-184 (2012) 30-45.

[27] Adi T. Utomo, Heiko Poth, Phillip T. Robbins, Andrzej W. Pacek, Experimental and theoretical studies of thermal conductivity, viscosity and heat transfer coefficient of titania and alumina nanofluids, International Journal of Heat and Mass Transfer 55 (2012) 77727781.

[28] P. C. Mukesh Kumar, K. Palanisamy, J. Kumar, R. Tamilarasa, S. Sendhilnathan, CFD analysis of heat transfer and pressure drop in helically coiled heat exchangers using $\mathrm{Al}_{2} \mathrm{O}_{3} /$ water nanofluid, Journal of Mechanical Science and Technology 29 (2) (2015) 697-705.

[29] Ramin Hajian, Mohammad Layeghi, Kamal Abbaspour Sani, Experimental study of nanofluid effects on the thermal performance with response time of heat pipe, Energy Conversion and Management 56 (2012) 63-68.

[30] Yanjun Li, José Fernández-Seara b , Kai Du, Ángel Álvarez Pardiñas, Luis Lugo Latas, Weixue Jiang, Experimental investigation on heat transfer and pressure drop of $\mathrm{ZnO} /$ Ethylene Glycol-Water nanofluids in transition flow, Applied Thermal Engineering, http://dx.doi.org/doi: 10.1016/j.applthermaleng.2015.09.020.

[31] S.J. Chung, J.P. Leonard, I. Nettleship, J.K. Lee, Y. Soong, D.V. Martello, M.K. Chyu, Characterization of $\mathrm{ZnO}$ nanoparticle suspension in water: effectiveness of ultrasonic dispersion, Powder Technol. 194 (2009) 75-80.

[32] Yi-Hsuan Hung, Tun-Ping Teng, Bo-Gu Lin, Evaluation of the thermal performance of a heat pipe using alumina nanofluids, Experimental Thermal and Fluid Science 44 (2013) 504-511. 
